\title{
Relationship between large-scale ionospheric field-aligned currents and electron/ ion precipitations: DMSP observations
}

\author{
Chao Xiong ${ }^{1 *}$ (D, Claudia Stolle ${ }^{1,2}$, Patrick Alken ${ }^{3}$ and Jan Rauberg ${ }^{1}$
}

\begin{abstract}
In this study, we have derived field-aligned currents (FACs) from magnetometers onboard the Defense Meteorological Satellite Project (DMSP) satellites. The magnetic latitude versus local time distribution of FACs from DMSP shows comparable dependences with previous findings on the intensity and orientation of interplanetary magnetic field (IMF) $B_{y}$ and $B_{z}$ components, which confirms the reliability of DMSP FAC data set. With simultaneous measurements of precipitating particles from DMSP, we further investigate the relation between large-scale FACs and precipitating particles. Our result shows that precipitation electron and ion fluxes both increase in magnitude and extend to lower latitude for enhanced southward IMF $B_{z^{\prime}}$ which is similar to the behavior of FACs. Under weak northward and southward $B_{z}$ conditions, the locations of the R2 current maxima, at both dusk and dawn sides and in both hemispheres, are found to be close to the maxima of the particle energy fluxes; while for the same IMF conditions, R1 currents are displaced further to the respective particle flux peaks. Largest displacement (about $3.5^{\circ}$ ) is found between the downward R1 current and ion flux peak at the dawn side. Our results suggest that there exists systematic differences in locations of electron/ion precipitation and large-scale upward/downward FACs. As outlined by the statistical mean of these two parameters, the FAC peaks enclose the particle energy flux peaks in an auroral band at both dusk and dawn sides. Our comparisons also found that particle precipitation at dawn and dusk and in both hemispheres maximizes near the mean R2 current peaks. The particle precipitation flux maxima closer to the R1 current peaks are lower in magnitude. This is opposite to the known feature that R1 currents are on average stronger than R2 currents.
\end{abstract}

Keywords: Field-aligned currents, Aurora, Particle precipitation, DMSP

\section{Introduction}

Auroral field-aligned currents (FACs), also known as Birkeland currents, are an important transport mechanism for energy and momentum between the magnetosphere and ionosphere and thus are of fundamental importance for understanding the solar wind-magnetosphere-ionosphere-thermosphere coupling (e.g., Milan et al. 2017). The distribution of FACs largely depends on the orientation of the interplanetary magnetic field (IMF), while the intensity is also modulated by the solar wind electric

\footnotetext{
*Correspondence: bear@gfz-potsdam.de

${ }^{1}$ GFZ German Research Centre for Geosciences, Telegrafenberg,

14473 Potsdam, Germany

Full list of author information is available at the end of the article
}

field and ram pressure, as well as ionospheric conductance (Korth et al. 2010). Solar irradiation flux variations can slightly affect the intensity of FACs, e.g., through modulation of ionospheric conductivity, but the solar wind forcing has been demonstrated to dominate FAC distributions (e.g., Edwards et al. 2017). For southward IMF conditions, the FACs exhibit a consistent pattern of two concentric rings flowing in and out of the ionosphere, labeled as poleward Region 1 (R1) and equatorward Region 2 (R2) currents (Iijima and Potemra 1976a, b), while for northward IMF condition, an additional poleward current system is often observed in the dayside cusp region, known as "NBZ" or "Region 0" currents (e.g., Iijima et al. 1984; Milan et al. 2000). 
The global distribution of FACs and their variations have been widely investigated using magnetometer measurements on board low Earth orbital (LEO) satellites, like Triad (e.g., Armstrong and Zmuda 1975; Iijima and Potemra 1976a, b), OGO 5 (Orbiting Geophysical Observatory) (e.g., Sugiura 1975), Freja (e.g., Lühr et al. 1996), Dynamics Explorer 2 (e.g., Weimer 2001), Ørsted (e.g., Papitashvili et al. 2002), or CHAMP (Challenging Minisatellite Payload) (e.g., Wang et al. 2005). However, as pointed out by Lühr et al. (1996), computing FACs along track from such single-satellite mission has always suffered from non-uniqueness. As the satellite moves through three-dimensional regions of high current density, the recorded magnetic field changes can be interpreted in terms of current density only if certain assumptions are made: the currents are static over the time of spacecraft measurements and have a simple geometric configuration, e.g., the sheet of FACs is elongated approximately east-west, and perpendicular to the satellite orbit (Lühr et al. 2020). Later with the development of satellite constellations, like Cluster II (e.g., Escoubet et al. 2001), ST5 (e.g., Slavin et al. 2008; Gjerloev et al. 2011), as well as the recent Swarm mission (e.g., Ritter et al. 2013; Dunlop et al. 2015; Trenchi et al. 2019), FACs' density estimations are made using simultaneous measurements from multi-point data spanning a two-dimensional area in space. By comparing FACs derived from single- and dual-satellite of Swarm, Lühr et al. (2015) found that at the auroral latitudes, the large-scale FAC signatures are consistent between the two approaches, but discrepancies commonly appear poleward of $75^{\circ}$ magnetic latitude (MLAT). Filamentary FAC signatures are captured by the dual-satellite approach at poleward auroral oval under northward IMF condition, but are missed by the single-satellite technique. Another application of a multi-satellite approach to calculate FACs is the Active Magnetosphere and Planetary Electrodynamics Response Experiment (AMPERE) project (e.g., Anderson et al. 2000; Green et al. 2009; Korth et al. 2010). Twodimensional average configurations of FACs are derived at cadences of less than an hour from magnetic measurements of 66 Iridium satellites.

FACs can be carried by either electrons or ions, but the dominant carriers are thought to be magnetospheric/ionospheric electrons flowing along the magnetic field lines. It was observed that contribution to FACs from downward precipitating electrons exceeds that of upward flowing ionospheric ions typically by an order of magnitude (e.g., Cattell et al. 1979). Several studies have been carried out for resolving the relationship between FACs and particle precipitations. Focusing on large-scale upward FACs and electron precipitations, Korth et al. (2014) have compared simultaneous observations of FACs derived from
AMPERE and $\mathrm{N}_{2}$ Lyman-Birge-Hopfield (LBH) auroral emission measured by the Global Ultraviolet Imager (GUVI) on board the Thermosphere, Ionosphere, and Mesosphere Energetics and Dynamics (TIMED) satellite. The electron precipitation is inferred from a statistical relation between LBH intensity and electron energy flux (Sotirelis et al. 2013). They found that for southward IMF, the electron precipitation occurred primarily within and near large-scale upward currents, while such correspondence between upward currents and electron precipitation is less evidenced for northward IMF condition. In another study, Robinson et al. (2018) have reexamined the relation between FACs from AMPERE and LBH auroral emission from GUVI, but used a different empirical function as that from Zhang and Paxton (2008) to convert the LBH intensity to electron energy flux. They have combined the upward and downward currents, and found that the particle energy flux correlates well with FACs intensity, showing strongest dependence near magnetic midnight hours. Carter et al. (2016) have investigated FACs from AMPERE with the aurora ultraviolet (UV) emission from Imager for Magnetopause-to-Auroral Global Exploration (IMAGE) mission. They found that the $\mathrm{R} 2$ current is more closely aligned with the distribution of auroral UV emission than the R1 current, whether that be in the discrete auroral zone of dusk or in the postmidnight diffuse aurora sector. This finding is different from the result of Korth et al. (2014), who concluded that the upward R1 current at dusk has a better dependence on the electron precipitation than the upward R2 current at dawn. Therefore, the relation between FACs and particle precipitations is still an open issue, which encourages further investigation.

In the studies of Korth et al. (2014) and Carter et al. (2016), they have compared FACs and particle precipitations derived from different missions, the AMPERE and GUVI as well as AMPERE and IMAGE. When comparing measurements between different missions, the separations in temporal and spatial coverage between the mission pair might lead to differences in interpreting their results. For example, Carter et al. (2016) tried to make their comparison consistent by sorting the FACs and IMAGE emissions into bins under similar IMF orientations, as there is no overlap between the AMPERE and IMAGE missions. Therefore, applying direct comparisons between FACs and particle precipitations from the same platform allows for temporal overlap. This study utilizes simultaneous magnetic and particle precipitation measurements from the Defense Meteorological Satellite Project (DMSP). The magnetic measurements of DMSP have earlier been used for investigating, e.g., the dayside FAC source regions (Wing et al. 2010), magnetic perturbations at polar cap during geomagnetic storms 
(Knipp et al. 2014), and pointing flux in the dayside polar cap boundary regions (Lu et al. 2018). Here, we derive statistical analysis of FAC signatures from DMSP, especially from the recent F16-F18 satellites. Additionally, the DMSP data set allows investigating contributions from precipitating electron and ions separately. In "Dataset Section", we shortly introduce the DMSP mission as well as its magnetic and precipitation measurements. In "Observations Section", we first verify the reliability of FAC signatures derived from DMSP by comparing to nearly simultaneous Swarm measurements. Then, the IMF dependence and relation between the FACs and precipitation particles observed by DMSP are discussed. Evaluations against previous studies are provided in "Discussion Section". Finally, we summarize the main findings in "Summary Section".

\section{Dataset}

The special sensor magnetometer (SSM) and special sensor $\mathrm{J}$ (SSJ) measurements from DMSP as well as the magnetic measurements from Swarm

DMSP is a series of Earth-observing spacecraft since 1962. In this study, we used observations from satellites F-16, F-17, and F-18, that fly in Sun-synchronous, nearpolar orbits, with inclinations of about $98.8^{\circ}$ and periods of about 102 min (Burke et al. 2011). The three DMSP satellites all carry the SSM, which is a triaxial fluxgate magnetometer consisting of three separate cores to measure the magnetic field components in a range of $\pm 63,553 \mathrm{nT}$ and with an accuracy of $2 \mathrm{nT}$ (Kilcommons et al. 2017). Alken et al. (2014) have calibrated the SSM dataset from DMSP F16-F18 for modeling the Earth's main field. The calibrated dataset have been extended until the end of 2016 by Alken et al. (2020). The SSM data are provided with time resolution of $1 \mathrm{~Hz}$. These data are used for deriving FACs in this study. Measurements from the Special Sensor J (SSJ/5) instrument sense precipitating electrons and ions with energy flux between $30 \mathrm{eV}$ and $30 \mathrm{keV}$. SSJ/5 data from DMSP F16-F18 satellites during a 5-year period (2010-2014) have been calibrated by Redmon et al. (2017) and are publicly accessible at https ://satdat.ngdc.noaa.gov/dmsp/data/f18/ssj/.

Figure 1 (middle panel) shows the altitude evolution of DMSP F-16 (black), F-17 (blue), and F-18 (red) from 2009 to the end of 2016. For this period, Alken et al. (2020) provided calibrated magnetic data from DMSP. The three satellites fly at about $850 \mathrm{~km}$, and their local time coverages (bottom panel) are in the evening for ascending nodes (thick-solid lines) and in the morning for descending nodes (thin-dotted lines). Their orbits drift very slightly in local time. In "Justification of FACs derived from DMSP Section", we show one example of the Swarm observations to compare with DMSP data, and thus, the altitude and local time evolution of Swarm A has also been added, here marked in green. Swarm A flies at about $460 \mathrm{~km}$ altitude which is slowly decaying. The orbit of Swarm A drifts in local time, which needs about 133 days for covering 24-h local times (see also Xiong et al. 2016). On Swarm, the magnetic field is measured by a vector field magnetometer (VFM) and an absolute scalar magnetometer (ASM), and the latter one is used to calibrate the vector field. The VFM is a high precision instrument capable of magnetic field measurements with time resolution up to $50 \mathrm{~Hz}$ and a precision of about $0.1 \mathrm{nT}$. In the example, we use magnetic time series of Swarm with time resolution of $1 \mathrm{~Hz}$.

\section{FACs derived from DMSP magnetic measurements}

To isolate ionospheric sources in geomagnetic measurements, geomagnetic field contributions from the Earth's core, crust, and magnetosphere are estimated by the CHAOS-6 model (Finlay et al. 2015) and removed from the data. The satellite-based residual observations are applied to estimate radial and field-aligned currents in the ionosphere. The basic equation for deriving electric currents from magnetic measurements is Ampère's law and it is for the vertical current component $j_{z}$ :

$$
j_{z}=\frac{1}{\mu_{0}}\left(\frac{d b_{y}}{d x}-\frac{d b_{x}}{d y}\right)
$$

where $b_{x}$ and $b_{y}$ are the magnetic field components caused by the currents, $x$ and $y$ are the coordinates in northward and eastward direction of the NEC frame (north, east, center), respectively, and $\mu_{0}$ is the permeability of free space. The radial currents are then transferred to FACs by projection into the direction of the local magnetic field line (see also Ritter et al. 2013).

The residual magnetic field data from DMSP have been applied in a processor originally developed for the Swarm mission, to derive FAC data set of DMSP. Since the temporal resolutions of the Swarm and DMSP time series are both $1 \mathrm{~Hz}$, no additional adaptation was applied in the processor. Stolle et al. (submitted to Earth Planets and Space) reported that large-scale FACs are well captured by non-high-precision magnetometer in space. The DMSP FAC data of F16-F18 during 2009-2016 are available at ftp://magftp.gfz-potsdam.de/DMSP/FAC/. For verification with DMSP FACs, we apply an example of Swarm as provided as daily product through ESA.

Particle precipitation data from DMSP F-16 to F-18 provided by Redmon et al. (2017) covers a 5-year period from 2010 to 2014 (indicated by light-orange shadow in Fig. 1). Therefore, we focused also on this 5-year period to investigate DMSP FAC data. The solar flux variation for this period is shown in the top panel of Fig. 1. The 


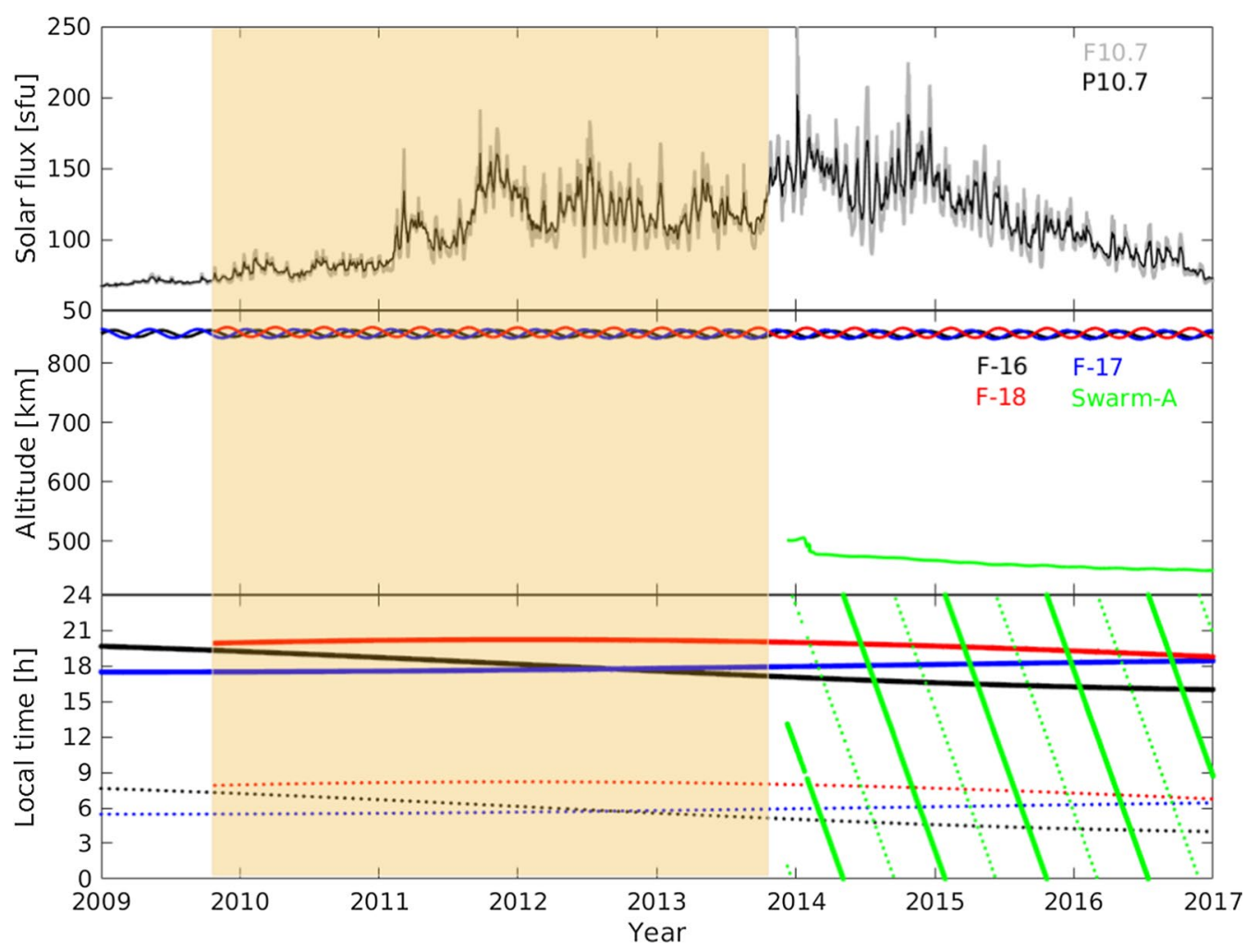

Fig. 1 (Top panel) The variation of solar flux, F10.7 (gray) and P10.7 (black), from 2009 to the end of 2016. (middle panel) The altitude evolutions of DMSP F-16 (black), F-17 (blue), F-18 (red), and Swarm A (green). (bottom panel) The local time evolutions of the four satellites, separately for ascneding (thick-solid) and descending (thin-dotted) nodes. The light-orange shaded area represents the period of available particle energy flux data from DMSP

mean value of the P10.7 index between 2010 and 2014 is $116.3 \mathrm{sfu}$.

\section{Observations \\ Example of magnetic and particle precipitations data measured by DMSP}

Figure 2 shows a high-latitude orbital segment of DMSP F-18 around 16:45 UTC on 5 February 2014. The first panel shows the three components of magnetic residuals to the CHAOS-6 model predictions, $\Delta b$, with $x, y$, and $z$ pointing to the north, east, and center of the Earth. Both $\Delta b_{x}$ and $\Delta b_{y}$ show fluctuations of about $\pm 200 \mathrm{nT}$ above $70^{\circ}$ magnetic Apex latitude (Emmert et al. 2010, hereafter called MLAT), while $\Delta b_{z}$ is much smoother. Occasional step-like jumps in $\Delta b_{z}$ are remainders from the calibration process (Alken et al. 2020); however, they do not affect the FACs calculation [see Eq. (1)]. As expected, FACs of amplitudes within $\pm 5 \mu \mathrm{A} / \mathrm{m}^{2}$ in the second panel are derived where $\Delta b_{x}$ and $\Delta b_{y}$ show small-scale fluctuations.
The SSJ/5 instrument on board DMSP uses 20 channels detecting precipitating electrons and ions. Differential energy fluxes derived from each channel are added up to get the integrated energy flux. It is then divided by the number of observed counts to get an average energy of electrons and ions (Hardy et al. 2008; Redmon et al. 2010). The lower panels of Fig. 2 show the integrated electron energy flux, the electron average energy (AVG), the integrated ion energy flux, and the ion average energy. An elevated level of precipitating electrons appears at around $\pm 70^{\circ}$ MLAT and stays higher inside the polar cap than equatorward of the precipitation maxima. The ion precipitation data are sparser; however, an increased level is still recognized at a few degrees higher latitude than for the electron precipitation in this example. Here, the precipitating electrons and ions fluxes reach to lower latitudes than the intense FACs. In the study, we compare FAC pattern with the electron and ion energy fluxes, but not with the average energy. Carter et al. (2016) and Korth et al. (2014) similarly compared derived electron energy fluxes with FAC patterns. 


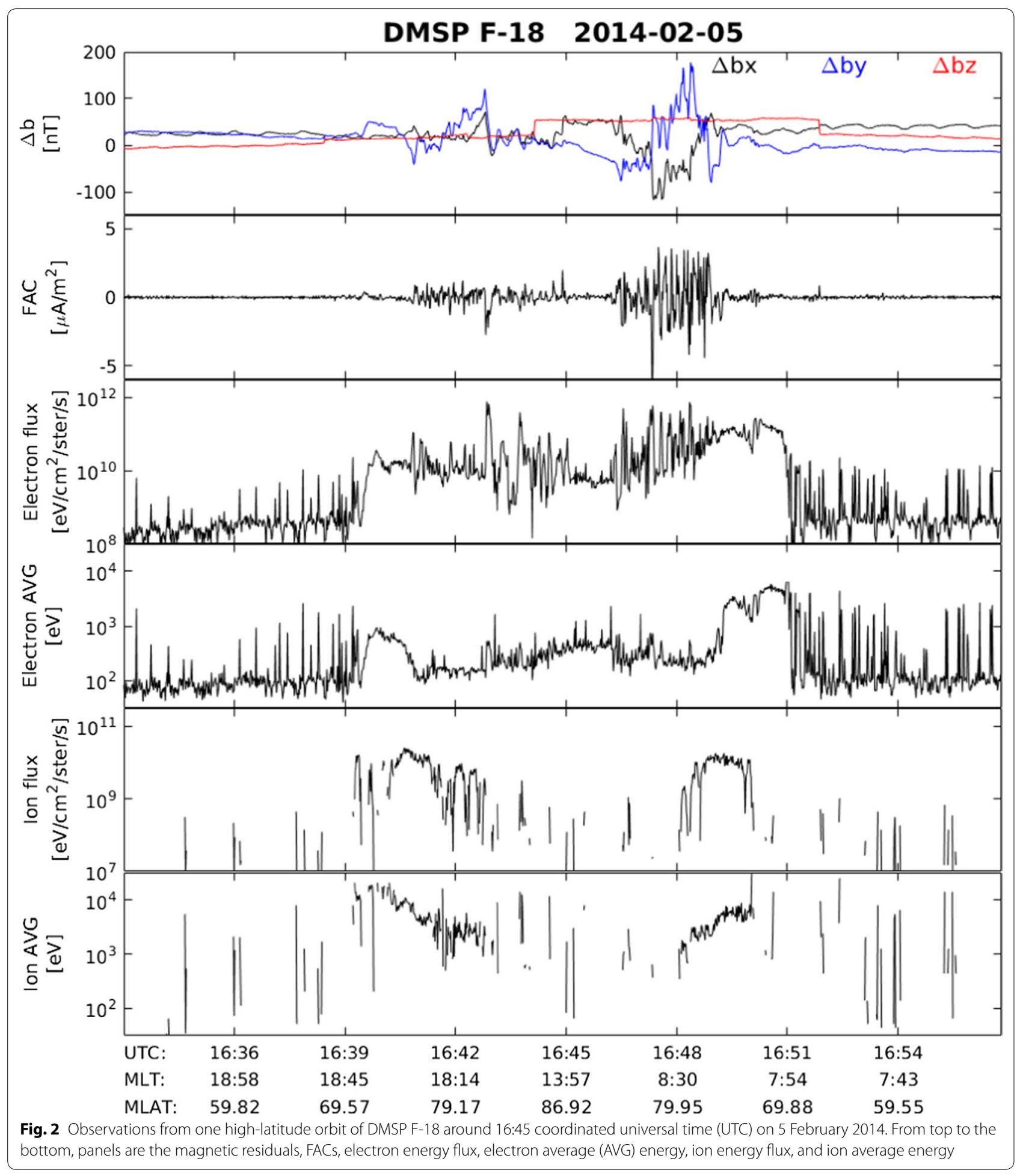

\section{Justification of FACs derived from DMSP}

Figure 3 shows FAC observations along the same DMSP F-18 orbital segments on 5 February 2014 together with the Swarm A orbit that has been spatially and temporally close. Both satellites have been counter-rotating at similar magnetic local times, and the UTC difference at the highest magnetic latitude of their respective orbit was about 14 min. Enhanced FAC signatures display at 
similar magnetic latitudes. The $1 \mathrm{~Hz}$ FAC time series by Swarm A including small-scale features shows slightly larger amplitudes (panel b). However, after applying a low-pass filter with a cut-off frequency of $20 \mathrm{~s}$ to the $1 \mathrm{~Hz}$ data (panel c) from both satellites, the large-scale structures show consistent features with similar amplitudes. Outside the auroral region, the noise level of the current intensity derived from Swarm A is within $\pm 0.02 \mu \mathrm{A} / \mathrm{m}^{2}$, while the DMSP-derived currents have a noise level of $0.15 \mu \mathrm{A} / \mathrm{m}^{2}$. Considering the largest amplitude of FAC on the dusk side of this event is about $\pm 3 \mu \mathrm{A} / \mathrm{m}^{2}$, this corresponds to 0.7 and $5 \%$ for Swarm A and DMSP, respectively. However, after applying a low-pass filter with cut-off frequency of $20 \mathrm{~s}$, the levels of intrinsic fluctuations derived from both satellites are less than $0.02 \mu \mathrm{A} /$ $\mathrm{m}^{2}$. This example suggests that FACs derived from DMSP compare well with observations from high precision data and are quite reliable. Similar conclusions can be derived from comparisons with DMSP F-16 and F-17 (not shown here).

Subsequently, we display the IMF dependence of FACs from DMSP. The data from all three DMSP satellites have been combined to achieve a wider local time coverage. A low-pass filter with a cut-off frequency of $20 \mathrm{~s}$ was applied to the $1 \mathrm{~Hz}$ FAC time series of DMSP to reflect large-scale FAC signatures. The data were sorted into MLAT $\left(1^{\circ}\right)$ and MLT (1 h) bins and plots for different levels of IMF magnitudes and orientations were created. Figure 4a shows the MLAT versus MLT distributions of the averaged FAC signatures from DMSP in the northern hemisphere. The subpanels are arranged by the intensity of IMF $B_{y}$ and $B_{z}$ components: from left to right, $B_{y}$ component varies from 10 to $-10 \mathrm{nT}$, and from top to bottom,, $B_{z}$ varies from 10 to $-10 \mathrm{nT}$, both in steps of $5 \mathrm{nT}$. Due to the low occurrence of data for $B_{y}$ or $B_{z}$ beyond $\pm 10 \mathrm{nT}$, results are not shown here. The lack of data around noon and midnight hours are due to DMSP's dawn-dusk orbits. For each subpanel, dusk/dawn is on the left/right, and noon/night is on the top/bottom. For enhanced southward $B_{z}$, the intensity of FACs increases, the R1 and R2 currents appear in a clearer pair pattern, and they expand to lower latitudes. For northward $B_{z}$, the known current pair NBZ appears poleward of the R1 sheet around local noon. Concerning the dependence on $B_{y}$, for example, the upward R1 current tends to extend from afternoon to noon hours when $B_{y}$ is more negative. Figure $4 \mathrm{~b}$ shows the distribution of FACs in the southern hemisphere, which basically shows similar dependence on the IMF $B_{z}$. The NBZ current is

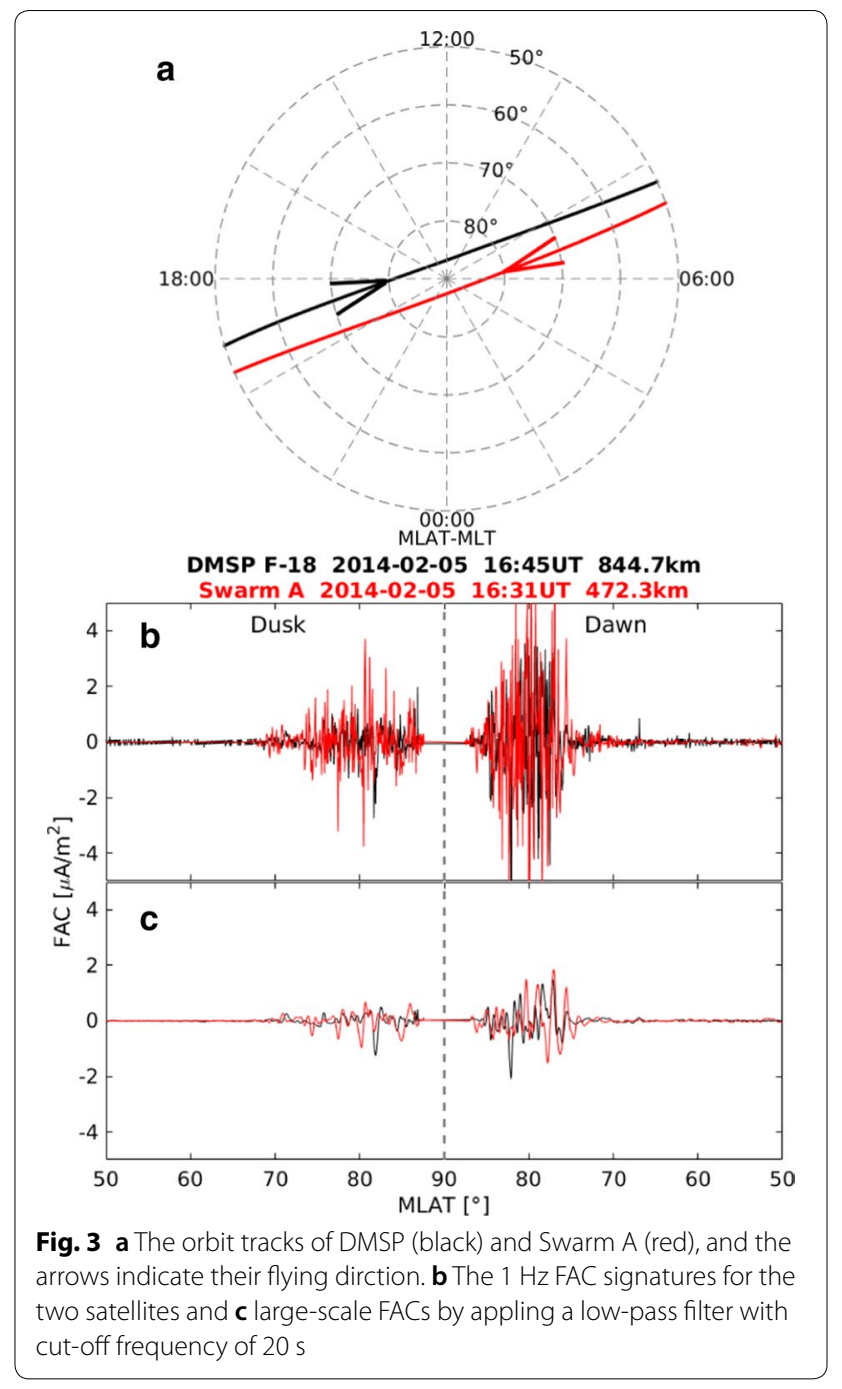

not monitored, as there is almost no data coverage around noon hours in the southern hemisphere. However, coverage is enhanced around midnight in the southern hemisphere. The IMF dependences of FAC shown in Fig. 4a, b compare well to those of previous publications (e.g., Wang et al. 2008; Korth et al. 2010; Milan et al. 2017; He et al. 2012; Coxon et al. 2014; Carter et al. 2016; Laundal et al. 2018). Furthermore, the FACs intensity in the northern hemisphere is slightly higher than that in the southern hemisphere, which is consistent with the findings of Coxon et al. (2016) and Workayehu et al. (2019). Another feature seen here is that the intensity of R1 currents is stronger than for $\mathrm{R} 2$ currents at both dawn and 


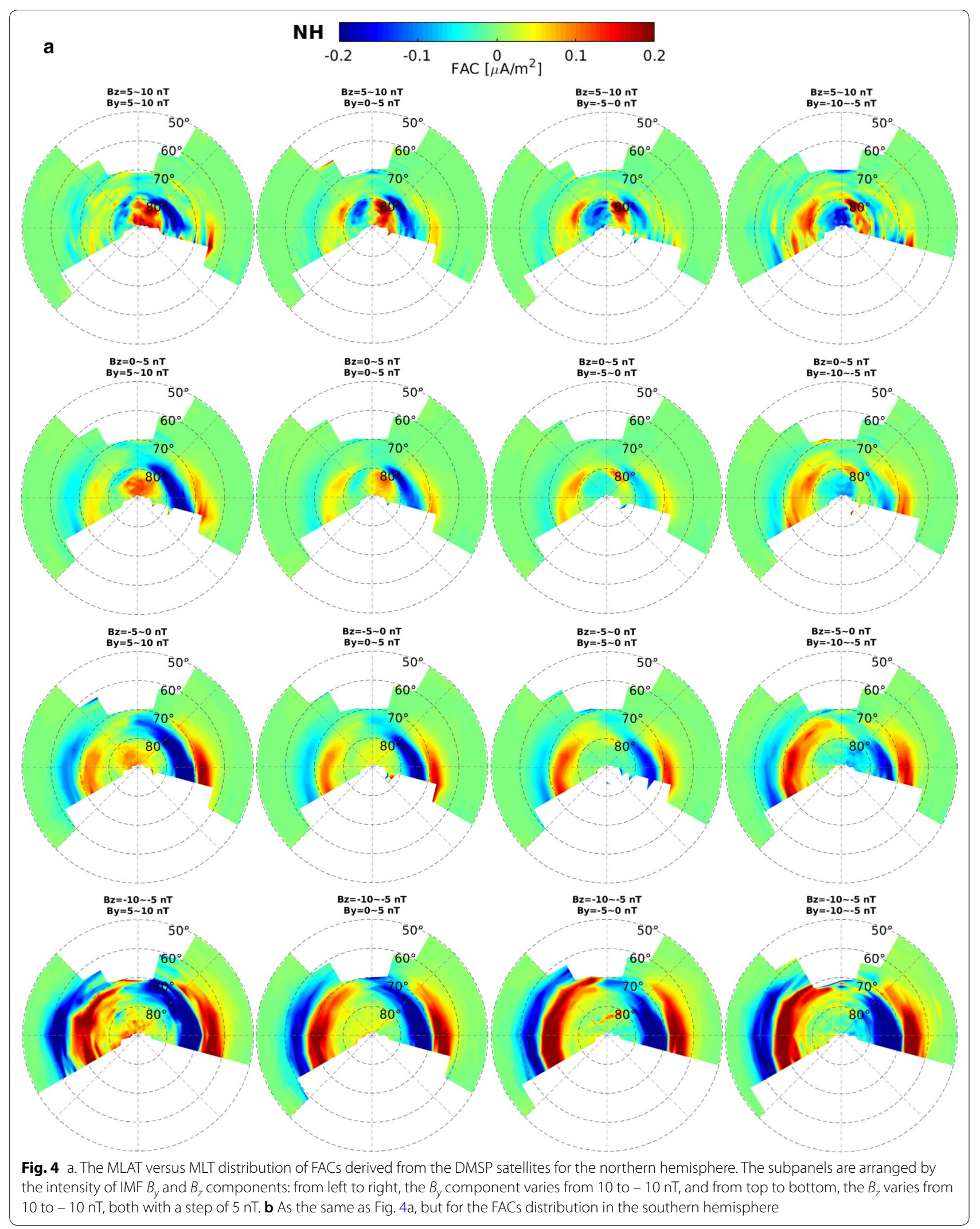




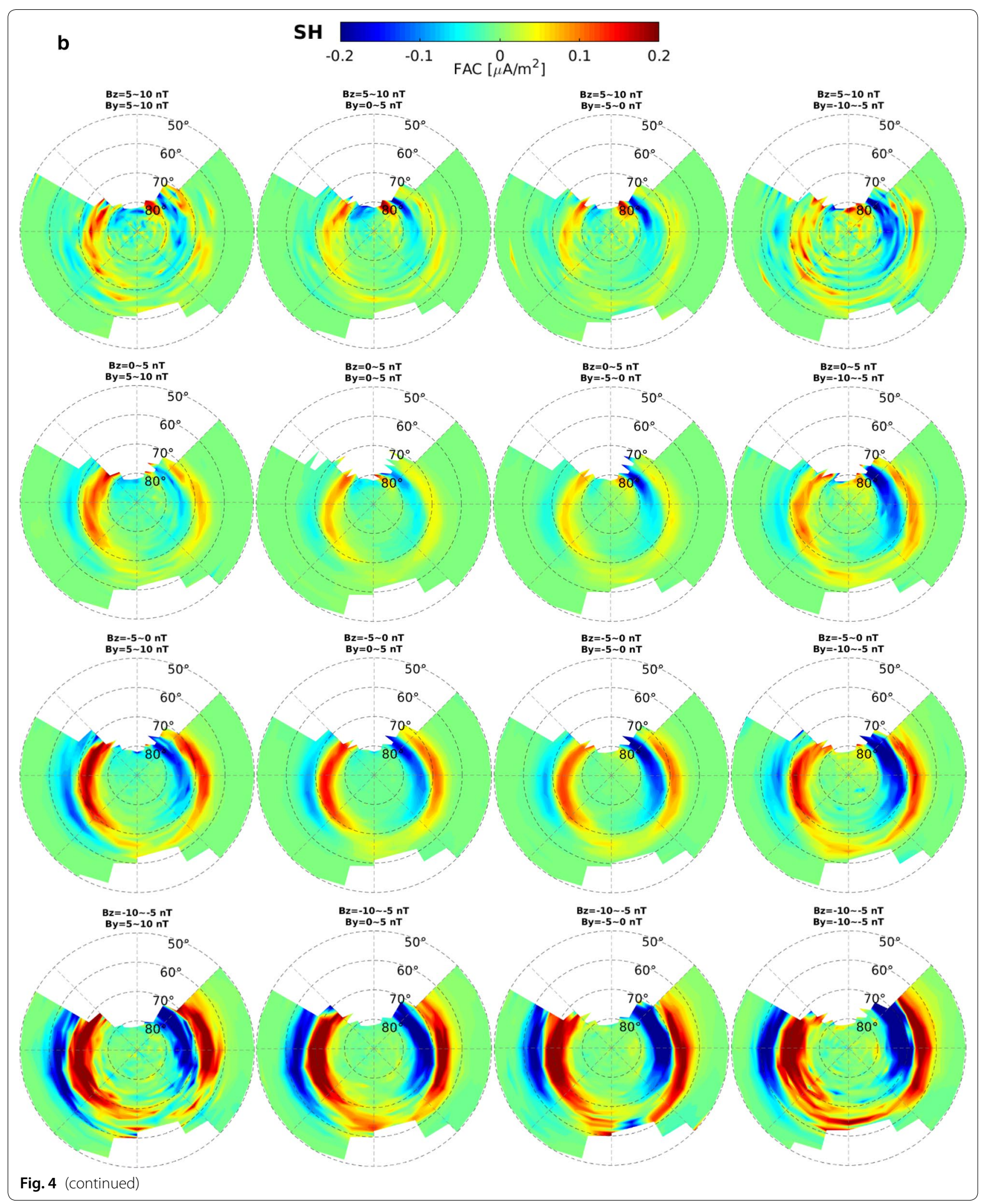


(x) $(x)(x)(n)$ $(-))(a)((-))(a)$ (a) $)((a))((-a))($ (a) $)$ 


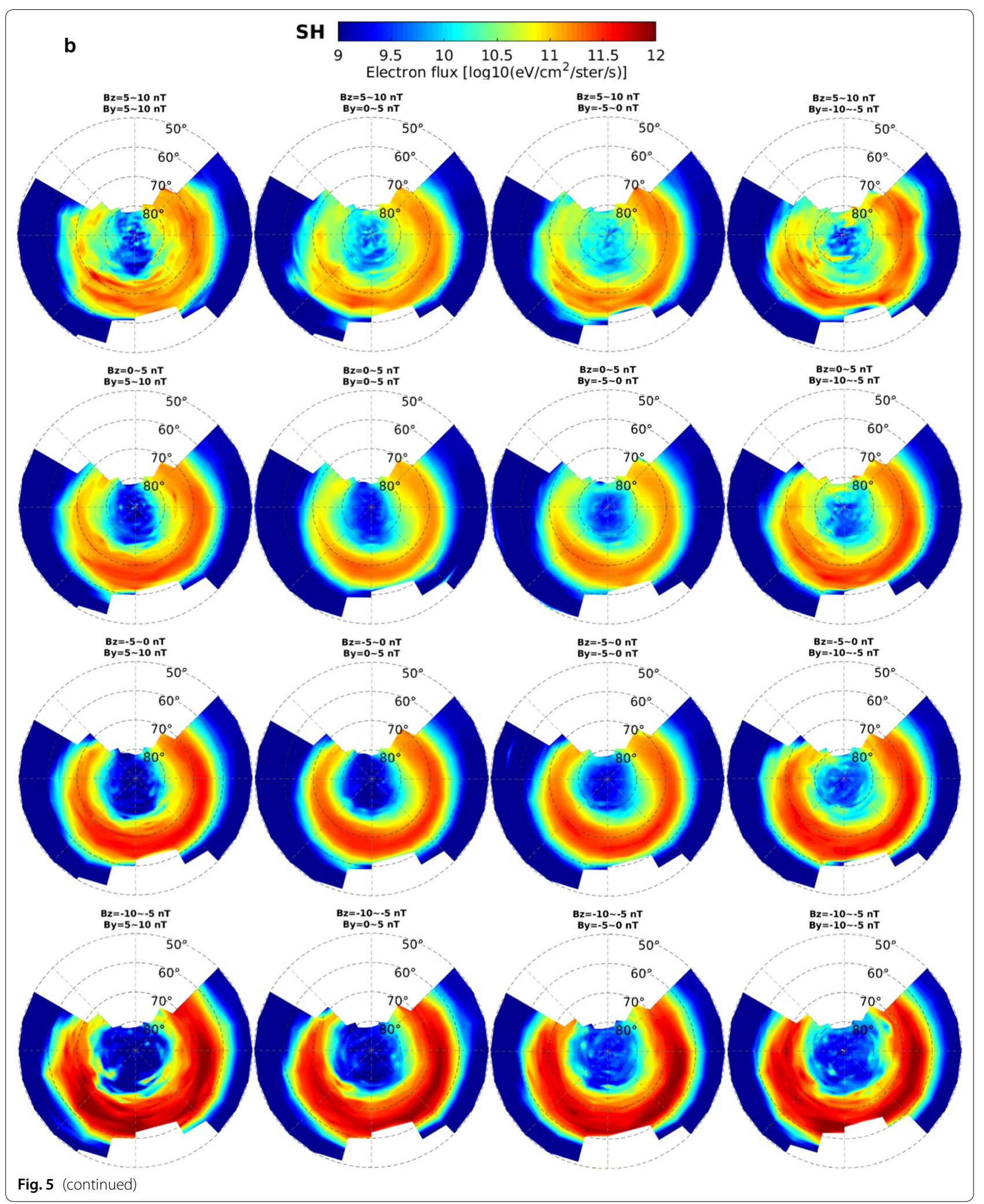


dusk sides, which is consistent with the previous findings (e.g., Christiansen et al. 2002; Le et al. 2010; Wang et al. 2019). All these comparisons further support the reliability of the DMSP FACs.

\section{Comparison between FACs and particle precipitations observed by DMSP}

Figure 5a, b shows the distribution of electron energy flux from DMSP in the two hemispheres, respectively. Similar to FACs, the electron energy flux increases with stronger southern $B_{z}$ and expands to lower latitude. During northward $B_{z}$, the electron energy flux is much weaker at dusk than at dawn, and this feature is true for both hemispheres. Figure $6 \mathrm{a}$, b shows the distribution of ion energy flux from DMSP in the two hemispheres, respectively. It also increases with southward $B_{z}$. However, its intensity is weaker at dawn than at dusk, being an opposite dawndusk asymmetry to the electron energy flux.

In the following analysis, we will concentrate on the morning and evening sector. Figure S1 of the appendix shows that data coverage of DMSP is uniform in these sectors. Figure 7 shows latitudinal profiles of DMSP FACs (black), and energy flux of electrons (blue) and ions (red) along the dusk-dawn meridian and averaged within $\pm 1.5 \mathrm{~h}$ MLT. The solid and dashed lines represent the values in the northern and southern hemispheres, respectively. The left and right columns show results for intense northward $(5 \sim 10 \mathrm{nT})$ and southward ( $-10 \sim-5 \mathrm{nT}) B_{z}$, respectively, and with varying $B_{y}$ condition for each subpanel. For visualization purpose, the values of electron and ion precipitations have been divided by factors of $1 \times 10^{12}$ and $1 \times 10^{11} \mathrm{eV} / \mathrm{cm}^{2} /$ ster/s, respectively. The intensity of all three quantities increase and they cover a more equatorward latitudinal range for southward $B_{z}$ than for northward $B_{z}$. For northward $B_{z}>5 \mathrm{nT}$, however, it is not straight forward to reliably separate the R1/R2 current along the dusk-dawn meridian, though the peaks of precipitating electrons and ions are well discernable. Therefore, the following comparison between FACs and precipitation will be conducted for $B_{z}<5 \mathrm{nT}$. The intensity of the ion flux is in average stronger on the dusk side, while the intensity of the electron energy flux is stronger in the dawn side. The peaks of electron energy flux at the dusk and dawn sides are located around $70^{\circ}$ MLAT and $64^{\circ}$ MLAT, while the peaks of the ion energy flux are located around $65^{\circ}$ and $68^{\circ}$ MLAT, respectively. In the following, peaks of all three quantities are identified, as is demonstrated in Fig. 8 for the profiles of lower right panel in Fig. 7. As expected, the locations of the peaks of the upward FACs correspond well to the peaks of electron energy flux, and the locations of the peaks of the downward currents correspond well to the peaks of the ion energy flux. Table 1 shows the locations (in MLAT) of peaks of upward/ downward FACs and electron/ion energy flux for all subpanels with $B_{z}<5 n T$, separately for the dusk and dawn sides as well as two hemispheres.

Table 2 shows the mean difference of all entries in Table 1, separately for the dusk and dawn sides and the two hemispheres. Positive values reflect that the electron/ion energy flux peak is located poleward of the upward/downward FACs peak, and negative values reflect its equatorward location. On average, larger differences occur between the locations of R1 currents and ion/electron flux peaks (especially at the dawn side), than for R2 currents. At R1, the particle flux peaks are poleward of the FAC peaks, while, at R2, the particle flux peaks are equatorward of the FAC peaks. Our results are in several points consistent with the findings of Carter et al. (2016), but in some points different from that of Korth et al. (2014). This will be discussed in more detail in "Discussion Section". Furthermore, Fig. 9 visualizes the mean locations of these peaks. The red/blue thick lines represent the upward/downward FACs, and the dot/cross within black circles represent the precipitation electron/ ions, respectively. Interestingly, the FAC peaks enclose the particle energy flux peaks at both dusk and dawn side and in both hemispheres.

\section{Discussion}

Earlier observations showed that there is generally an imbalance between the pair of opposite-flowing $\mathrm{R} 1$ and R2 FACs in both dawn and dusk sides, i.e., the total current flowing in R1 FACs exceeds that in R2 FACs, and as a result, there are net currents flowing into (out of) the ionosphere at the dawn (dusk) sides (e.g., Le et al. 2010). This feature is also evidenced in the DMSP measurements, as shown in Fig. 4. Previous theories predicted that R1 currents come from the low-latitude boundary layer of closed field lines or the high-latitude boundary layer of open field lines (Sonnerup, 1980; Tanaka, 1995), while the R2 currents originate in the inner magnetosphere or at the inner edge of the plasma sheet (Southwood 1977; Harel et al. 1981). Through this picture, the R1 currents are more directly linked to the IMF and respond in general faster to IMF variations than the R2 currents by tens of minutes (Kikuchi et al. 2000). As also seen here, the large-scale R1 and R2 currents appear much clearer as an opposite-flowing pair and their intensity increase for southward $B_{z}$. It also means that the absolute magnitude of an R1/R2 imbalance is larger for stronger southward $B_{z}$ and contributes to a significant part of the IMF-averaged imbalance between R1 and R2 currents. The intensity of precipitating electron and ion flux are shown in Figs. 5, 6, 7 for the same IMF conditions. Here, the electron energy flux is stronger at dawn (corresponding to the dawn-side 
$(x)(x)$ $(A)(-)(a)(a)$ $(-)(-)(-)(-)$ $(-)(-)(a)(a)$ 


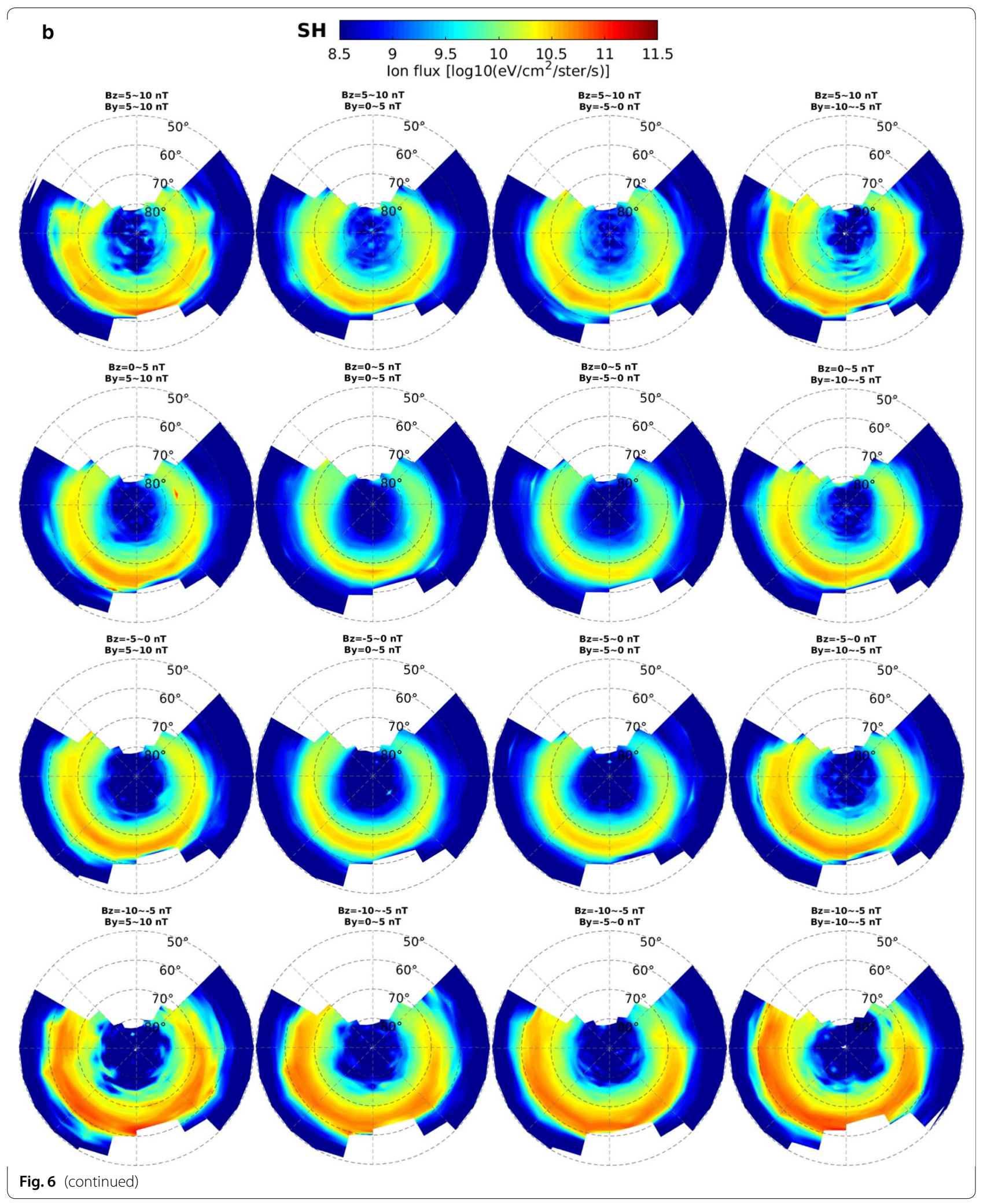



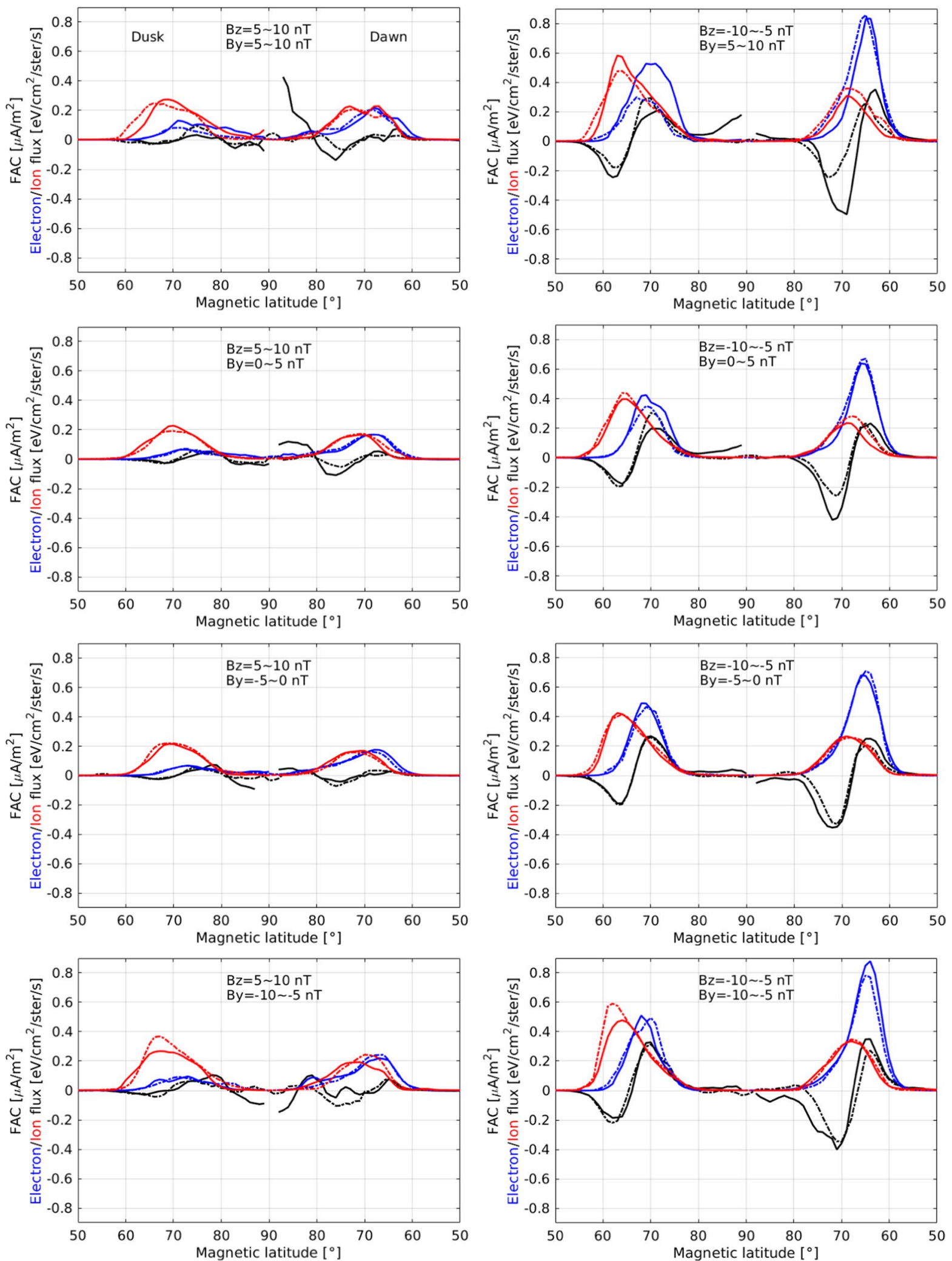

Fig. 7 The latitudinal profiles of FACs (black), energy flux of electron (blue) and ion (red), and quantities are averaged within $\pm 1.5 \mathrm{~h} \mathrm{MLT} \mathrm{centered}$ on the dusk-dawn meridian. The solid and dashed lines represent the values in the northern and southern hemispheres, respectively. Here, we show only the results for the more northward (left, $B_{z}=5-10 \mathrm{nT}$ ) and more southward (right, $B_{z}=-10--5 \mathrm{nT}$ ) $B_{z}$ conditions 


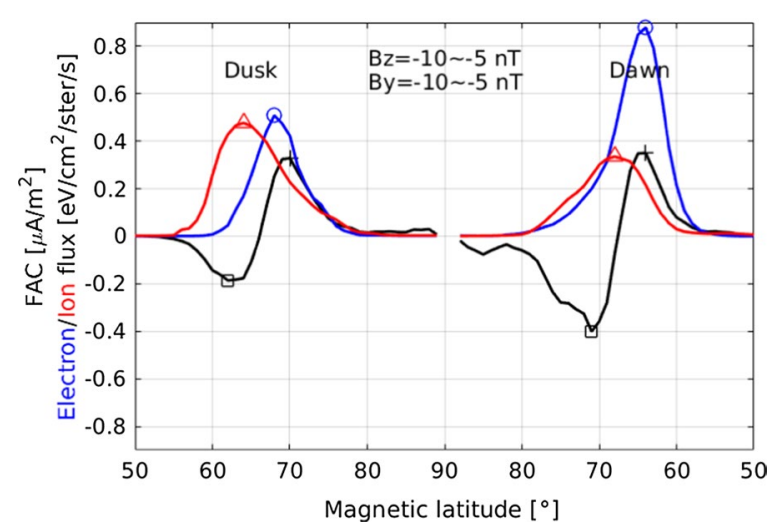

Fig. 8 The latitudinal profiles of FACs (black), electron (blue), and ion (red) in the northern hemisphere with $B_{z}$ and $B_{y}$ both within $-10--5 \mathrm{nT}$. For both dusk and dawn sides, the upward and downward peaks of FACs are marked with black cross and rectangle, while the peaks of electron and ions energy fluxes are marked with blue circle and red triangle, respectively upward R2 currents) than at dusk (corresponding to the dusk-side R1 currents), while the ion energy is stronger at dusk (corresponding to the dusk-side downward R2 currents) than at dawn (corresponding to the dawn-side downward R1 currents). This is in contrast to R1 currents being stronger than R2 currents. Although this observation is evident from the data, we can currently not provide a good explanation on the mechanism. However, it suggests that the R1/R2 currents are not solely determined by the intensity of downward particle energy flux.

Korth et al. (2014) found that under southward $B_{z}$, the distribution of electron energy flux agrees well with the dusk-side upward R1 current, but, on the dawn side, the upward R2 current shows wider latitudinal coverage and the peak is located a few degrees equatorward than that of the electron energy flux. They explained that, at dusk side, the electron precipitation is mainly due to field-aligned acceleration, while it is not the case for the

Table 1 The MLAT of peaks for upward/downward FAC, electron energy flux, and ion energy flux, separately for the dusk and dawn sides, as well as for the two hemisphere. Only the conditions with $\mathrm{Bz}<5 \mathrm{nT}$ have been considered

\begin{tabular}{|c|c|c|c|c|c|c|c|c|c|c|}
\hline & \multicolumn{2}{|l|}{ IMF } & \multicolumn{4}{|l|}{ Dusk } & \multicolumn{4}{|l|}{ Dawn } \\
\hline & $\mathrm{Bz}(\mathrm{nT})$ & By $(n T)$ & $\begin{array}{l}\text { upward } \\
\text { FAC (R1) }\end{array}$ & $\begin{array}{l}\text { Downward } \\
\text { FAC (R2) }\end{array}$ & Electron flux & Ion flux & $\begin{array}{l}\text { upward } \\
\text { FAC (R2) }\end{array}$ & $\begin{array}{l}\text { Downward } \\
\text { FAC (R1) }\end{array}$ & Electron flux & Ion flux \\
\hline \multirow[t]{12}{*}{$\mathrm{NH}$} & \multirow[t]{4}{*}{$0-5$} & $5-10$ & 74 & 67 & 74 & 68 & 66 & 75 & 67 & 70 \\
\hline & & $0-5$ & 76 & 69 & 74 & 69 & 68 & 76 & 68 & 71 \\
\hline & & $-5-0$ & 78 & 68 & 73 & 70 & 68 & 76 & 68 & 71 \\
\hline & & $-10--5$ & 74 & 67 & 72 & 68 & 68 & 73 & 68 & 69 \\
\hline & \multirow[t]{4}{*}{$-5-0$} & $5-10$ & 73 & 66 & 71 & 67 & 66 & 73 & 66 & 70 \\
\hline & & $0-5$ & 74 & 67 & 73 & 68 & 67 & 73 & 67 & 70 \\
\hline & & $-5-0$ & 74 & 67 & 72 & 68 & 68 & 74 & 68 & 71 \\
\hline & & $-10--5$ & 72 & 65 & 71 & 67 & 66 & 74 & 67 & 70 \\
\hline & \multirow[t]{4}{*}{$-10--5$} & $5-10$ & 72 & 62 & 69 & 63 & 63 & 69 & 64 & 69 \\
\hline & & $0-5$ & 71 & 64 & 69 & 65 & 64 & 72 & 66 & 69 \\
\hline & & $-5-0$ & 70 & 63 & 68 & 63 & 64 & 72 & 66 & 69 \\
\hline & & $-10--5$ & 70 & 62 & 68 & 64 & 64 & 71 & 64 & 68 \\
\hline \multirow[t]{12}{*}{ SH } & \multirow[t]{4}{*}{$0-5$} & $5-10$ & 75 & 67 & 71 & 68 & 68 & 74 & 67 & 70 \\
\hline & & $0-5$ & 75 & 68 & 73 & 69 & 68 & 75 & 69 & 72 \\
\hline & & $-5-0$ & 75 & 68 & 73 & 69 & 68 & 76 & 69 & 71 \\
\hline & & $-10--5$ & 73 & 66 & 72 & 68 & 67 & 74 & 67 & 70 \\
\hline & \multirow[t]{4}{*}{$-5-0$} & $5-10$ & 73 & 65 & 71 & 67 & 66 & 74 & 66 & 69 \\
\hline & & $0-5$ & 74 & 67 & 72 & 68 & 68 & 74 & 68 & 70 \\
\hline & & $-5-0$ & 74 & 67 & 72 & 68 & 68 & 74 & 68 & 70 \\
\hline & & $-10--5$ & 72 & 65 & 71 & 66 & 66 & 73 & 66 & 69 \\
\hline & \multirow[t]{4}{*}{$-10--5$} & $5-10$ & 70 & 63 & 67 & 64 & 65 & 73 & 65 & 69 \\
\hline & & $0-5$ & 70 & 63 & 69 & 64 & 65 & 71 & 65 & 68 \\
\hline & & $-5-0$ & 70 & 63 & 69 & 64 & 65 & 71 & 65 & 68 \\
\hline & & $-10--5$ & 70 & 62 & 70 & 62 & 64 & 70 & 65 & 68 \\
\hline
\end{tabular}


Table 2 The mean differences between the peaks of electron/ion energy flux and upward/downward FACs separately for dusk and dawn sides and two hemispheres. Only the conditions with $\mathrm{Bz}<5 \mathrm{nT}$ have been considered

\begin{tabular}{|c|c|c|c|c|}
\hline & \multicolumn{2}{|l|}{ Dusk } & \multicolumn{2}{|l|}{ Dawn } \\
\hline & $\begin{array}{l}\text { Electron flux } \\
\text { and upward } \\
\text { FAC (R1) }\end{array}$ & $\begin{array}{l}\text { lon flux } \\
\text { and downward } \\
\text { FAC (R2) }\end{array}$ & $\begin{array}{l}\text { Electron flux } \\
\text { and upward } \\
\text { FAC (R2) }\end{array}$ & $\begin{array}{l}\text { lon flux } \\
\text { and downward } \\
\text { FAC (R1) }\end{array}$ \\
\hline $\mathrm{NH}$ & $-2.0^{\circ}$ & $1.1^{\circ}$ & $0.6^{\circ}$ & $-3.4^{\circ}$ \\
\hline $\mathrm{SH}$ & $-1.8^{\circ}$ & $1.1^{\circ}$ & $0.2^{\circ}$ & $-3.8^{\circ}$ \\
\hline
\end{tabular}

precipitating electrons in the post-midnight to dawn sector where large population of diffused aurora electrons is observed (Meredith et al. 2003; Newell et al. 2009). Therefore, Korth et al. (2014) suggested that the distribution of upward current in dawn sector does not well agree with the distribution of precipitating electrons. However, this conclusion does not fully agree with our findings. As listed out in Table 2, on average, the electron energy flux shows smaller displacement with respect to the upward R2 current at dawn, compared to the dusk upward R1 current. Another difference is that, on both dusk and dawn sides, DMSP observed precipitating electrons show wider latitudinal extension than the upward FACs, while in Fig. 6 of Korth et al. (2014), the dawn-side upward R2 currents have a longer tail extending to lower latitudes.
Such difference might come from the FACs data processing from AMPERE. Carter et al. (2016) explained that the spatial resolution afforded by the spherical harmonic analysis of the historical Iridium data over a period of $2 \mathrm{~h}$ may not resolve the current structures measuring less than $3^{\circ}$ in latitude. In their analysis of Iridium data with $10 \mathrm{~min}$ resolution, they showed that the latitude extent of the currents is generally narrower than those obtained from $2 \mathrm{~h}$ resolution. The DMSP FACs are derived from $1 \mathrm{~Hz}$ magnetic data and the FACs have then be represented by a $20 \mathrm{~s}$ cut-off filter. The direct comparison with electron precipitation shows similar equatorial boundaries at dawn (see Figs. 7 and 8) and a high agreement of the location of the peaks of the R2 upward currents and electron precipitation.

To our knowledge, the relation of downward FACs and precipitating ions has not yet been investigated extensively. The electron energy flux is almost ten times larger than the ion (mostly proton) energy flux, and the contribution to the FACs from precipitating ions has usually been less discussed. Even though energetic protons are not an overall dominant energy source in the high-latitude region, they can be important at given location and time, for example near the equatorward boundary of the auroral oval in the afternoon and pre-midnight sectors (Hubert et al. 2001). Carter et al. (2016) also found that the downward R2 currents are allocated quite well with the auroral UV emission
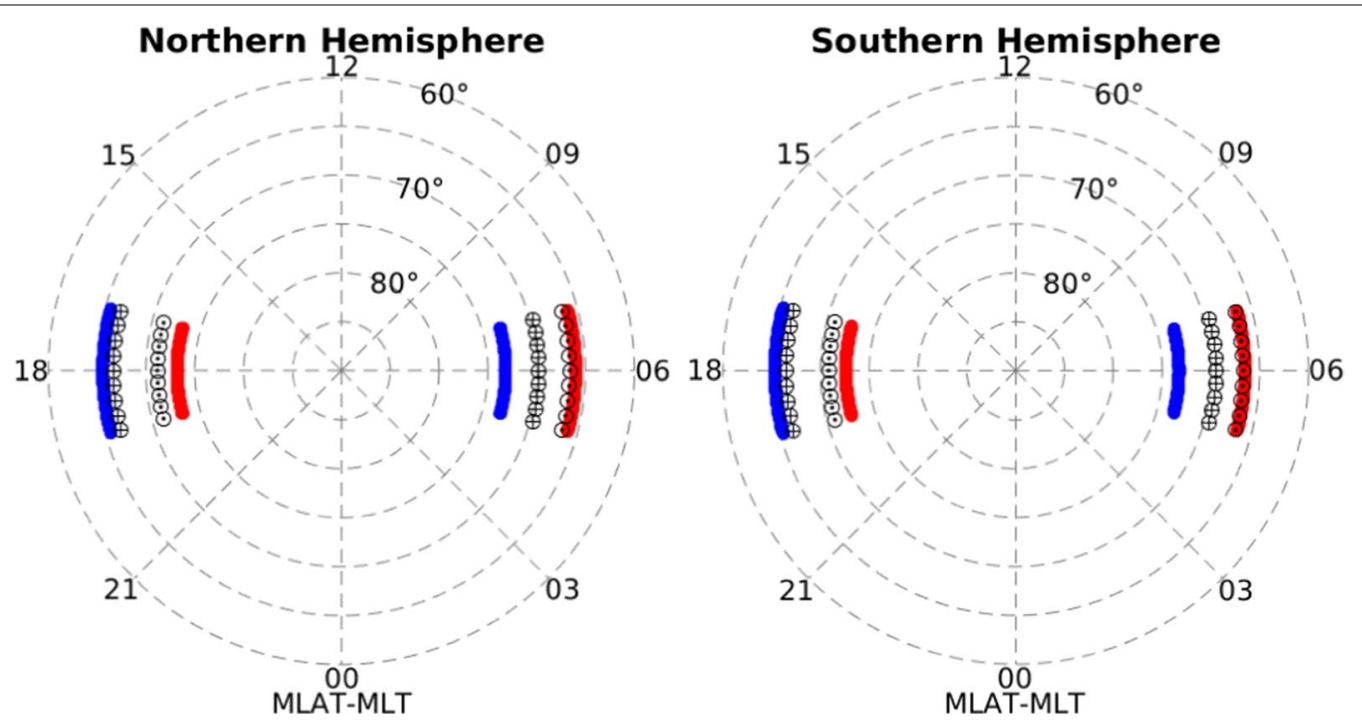

Fig. 9 The locations of the peaks of upward (red) and downward (blue) FACs, as well as the precipitation electrons (dot within black circle) and ions (cross within black circle) at dawn and dusk sides, and also in the two hemispheres 
caused by precipitating protons at the dusk side. Our results also show smaller displacement $\left(\sim 1^{\circ}\right)$ of the peaks between ion energy flux and downward R2 current at dusk side, while at dawn side, the precipitating ions are allocated more at the transition region between R1 and R2 currents and the peaks of the downward FACs and the ion energy flux is most displaced. Waters et al. (2001) commented that the post-midnight diffuse aurora is not necessarily produced solely by precipitating electrons, as diffuse auroral is brighter in the aurora far-ultraviolet (FUV) emission that corresponds to the distribution of precipitating protons. Murphy et al. (2013) also found that downward FACs typically occur in regions of diffuse aurora, but they did not separate whether the diffuse aurora was caused by precipitating electrons or protons. Our result suggests that downward R1 current is affected by both precipitating ions and electrons at the dawn side.

During comparison between Korth et al. (2014) and Carter et al. (2016), and our results, different observational limitations should also be considered when interpreting the similarities and differences. Both Korth et al. (2014) and Carter et al. (2016) used FACs estimates from AMPERE, while the former used $\mathrm{N}_{2} \mathrm{LBH}$ intensity to derive electron energy flux, and the later used wideband imaging camera (WIC) for representing the energy level of precipitation electrons. Both are indirect measurements of particle precipitation. Auroral emissions in the $\mathrm{N}_{2}$ LBH mainly reflect short (140-150 nm) and long (165-180 nm) wavelength ranges, and additional uncertainty exists in the empirical function between LBH intensity and electron energy flux (Robinson et al. 2018). WIC observations are continuously sensitive in the wavelength range from 140 to $190 \mathrm{~nm}$. In addition, both studies compared datasets derived from different missions, AMPERE/GUVI and AMPERE/IMAGE, respectively. As there is no overlap between the AMPERE and IMAGE missions, Carter et al. (2016) optimized their comparison by sorting the FACs and WIC emissions into bins under similar IMF orientations. However, differences in the temporal and spatial coverage of the different missions exist. The simultaneously FAC and particle precipitations measured from the same platform of DMSP overcome at least differences in temporal and spatial coverage.
We also want to point out that although earlier studies showed a satisfactory agreement between the IMAGEFUV observation and in situ particle measurements from satellites like FAST (Fast Auroral Snapshot Explorer) (Frey et al. 2001), DMSP (Gérard et al. 2001), and NOAA (National Oceanic and Atmospheric Administration) (Coumans et al. 2002), the DMSP SSJ5 instrument measures precipitating electrons/ions with energy range from $30 \mathrm{eV}$ to $30 \mathrm{keV}$. Precipitating particles out of this range may also contribute to the upward/downward currents, but cannot be captured by DMSP. Coumans et al. (2002) found that the contribution of protons with energy greater than $30 \mathrm{keV}$ can exceed that of protons with energy less than $30 \mathrm{keV}$, more often observed between 1600-2100 MLT (see their Figs. 11 and 12). In addition, the DMSP SSJ instrument measures only the downward precipitating particles, but not the upward particles, like ion outflow in the cusp region, is also expected to cause FAC signatures (e.g., Strangeway et al. 2000). Hence, any conclusive interpretation of differences between FACs and precipitating particles, as shown in our study, should consider that it was derived from measurements of downward particle precipitation within a limited energy range.

\section{Summary}

In this study, we have used simultaneous observations of magnetic field and particle precipitations from the DMSP F16, F17, and F18 satellites between 2010 and 2014, to investigate the spatial relation between large-scale FACs and precipitation particles. The main findings can be summarized as:

1. FACs derived from DMSP magnetic data have been compared with Swarm satellite observations and evaluated against earlier studies. Their amplitudes are similar and the MLAT versus MLT distributions show known dependence on the IMF $B_{y}$ and $B_{z}$ components, which confirms the reliability of the DMSP magnetic data set.

2. Electron and ion energy fluxes intensify and extend to lower latitudes for enhanced southward $B_{z}$, which is similar to the behavior of FACs. 
3. Under weak northward and under southward $B_{z}$ conditions, R2 current peaks, at both dusk and dawn sides and in both hemispheres, are found to be close to peaks of the particle energy fluxes. The particle fluxes are slightly shifted poleward to the R2 currents, in average about $1^{\circ}$ or less. For the same IMF conditions, the locations of the R1 currents and the respective particle flux peaks are even more displaced. The particle fluxes are shifted equatorward of the R 1 currents, in average about $2^{\circ}$ or more. The largest displacement is found between the downward $\mathrm{R} 1$ current and ion flux peak at the dawn side. Here, the ion flux peak is located about $3.5^{\circ}$ MALT equatorward of the R1 FAC peak at both hemispheres. Our results suggest that $\mathrm{R} 1$ current at dawn, often occurring together with diffuse auroras, is affected by both precipitating ions and electrons.

4. There exist systematic differences in the location of peaks of particle energy flux and large-scale FACs. On average, the FAC peaks enclose the particle energy flux peaks in an auroral band at both dusk and dawn sides and both hemispheres.

5. The particle precipitation, respectively, the electron or ion energy flux, both at dawn and dusk and in both hemispheres maximizes in average near the mean R2 current peaks. The particle precipitation maxima closer to the $\mathrm{R} 1$ current peaks are lower in magnitude. This is opposite to the known feature that R1 currents are on average stronger than R2 currents.

We still have to emphasize that the energy flux used in this study was based on limited energy levels and may affect these results. We support conclusions by Carter et al. (2016) that the large-scale FAC categorization into $\mathrm{R} 1$ and $\mathrm{R} 2$ areas is a simplification of a complex system of magnetosphere-ionosphere coupling, not necessarily described only by precipitating particles.

\section{Abbreviations}

FACs: Field-aligned currents; DMSP: Defense Meteorological Satellite Project; IMF: Interplanetary magnetic field; LEO: Low Earth orbital; OGO: Orbiting
Geophysical Observatory; CHAMP: Challenging Minisatellite Payload; MLAT: Magnetic latitude; EMPERE: Active Magnetosphere and Planetary Electrodynamics Responses Experiment; TIMED: Thermosphere, lonosphere, and Mesosphere Energetics and Dynamics; LBH: Lyman-Birge-Hopfield; GUVI: Global Ultraviolet Imager; UV: Ultraviolet; IMAGE: Imager for Magnetopauseto-Auroral Global Exploration; SSM: Special sensor magnetometer; SSJ: Special sensor J; VFM: Vector field magnetometer; ASM: Absolute scalar magnetometer; NEC: North, east, center; FUV: Far-ultraviolet; FAST: Fast Auroral Snapshot Explorer; NOAA: National Oceanic and Atmospheric Administration.

\section{Acknowledgements}

The authors would like to thank Dr. Hui Wang for discussion. The solar wind data are obtained from the NASA/GSFC OMNI facility. The European Space Agency (ESA) is gratefully acknowledged for providing Swarm data. The DMSP magnetometer data are publicly available from the NOAA National Geophysical Data Center (NGDC) through arrangement with the Air Force Research Laboratory (AFRL).

\section{Authors' contributions}

CX analyzed the FAC and particle precipitation data from DMSP, as well as the Swarm FAC measurements. PA processed and calibrated the magnetic measurements from DMSP. JR derived the FAC data set from DMSP magnetic data. CX and CS discussed aspects of data analysis and the content of the study. CX wrote and led the manuscript to which all authors contributed. All authors read and approved the final manuscript.

\section{Funding}

Open Access funding enabled and organized by Projekt DEAL. This study has partly been supported by AEBS project under subcontract No. SW-CO-DTUGS-112 within ESA's DISC under contract No. 4000109587/13/I-NB, and by project number 273453909 within the Priority Program 1788 "Dynamic Earth" funded by the German Research Foundation.

\section{Availability of data and materials}

The solar wind data are available at https://omniweb.gsfc.nasa.gov. The Swarm FAC data can be downloaded at https://swarm-diss.eo.esa.int. The DMSP FACs data are available at ftp://magftp.gfz-potsdam.de/DMSP/FAC/, and the particle precipitation data are available at https://satdat.ngdc.noaa.gov/dmsp/data/ f18/ssj/.

\section{Competing interests}

The authors declare that they have no competing interests.

\section{Author details}

${ }^{1}$ GFZ German Research Centre for Geosciences, Telegrafenberg, 14473 Potsdam, Germany. ${ }^{2}$ Faculty of Science, University of Potsdam, Potsdam, Germany. ${ }^{3}$ University of Colorado Boulder, Boulder, CO, USA.

\section{Appendix}

See Fig. 10. 


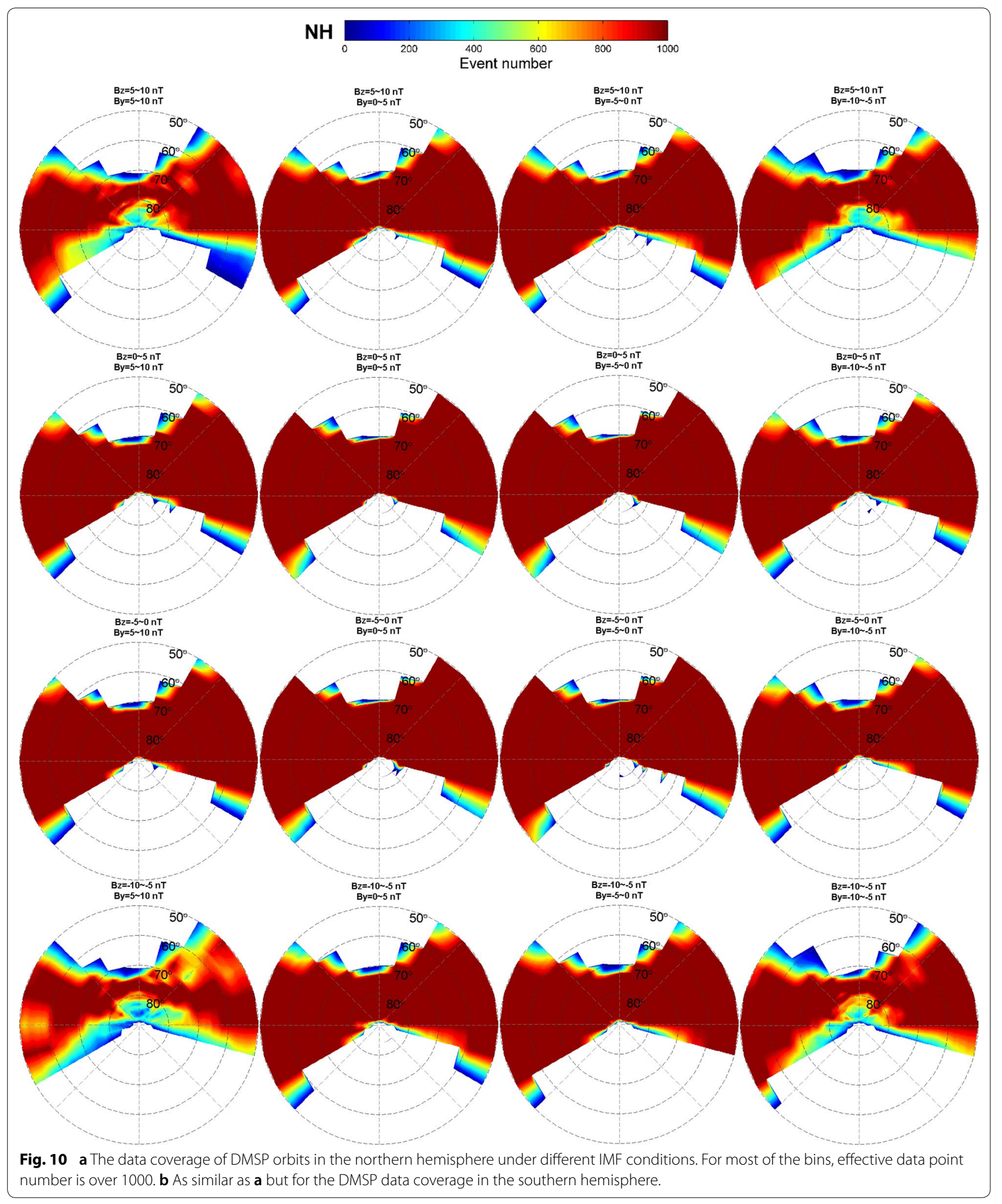




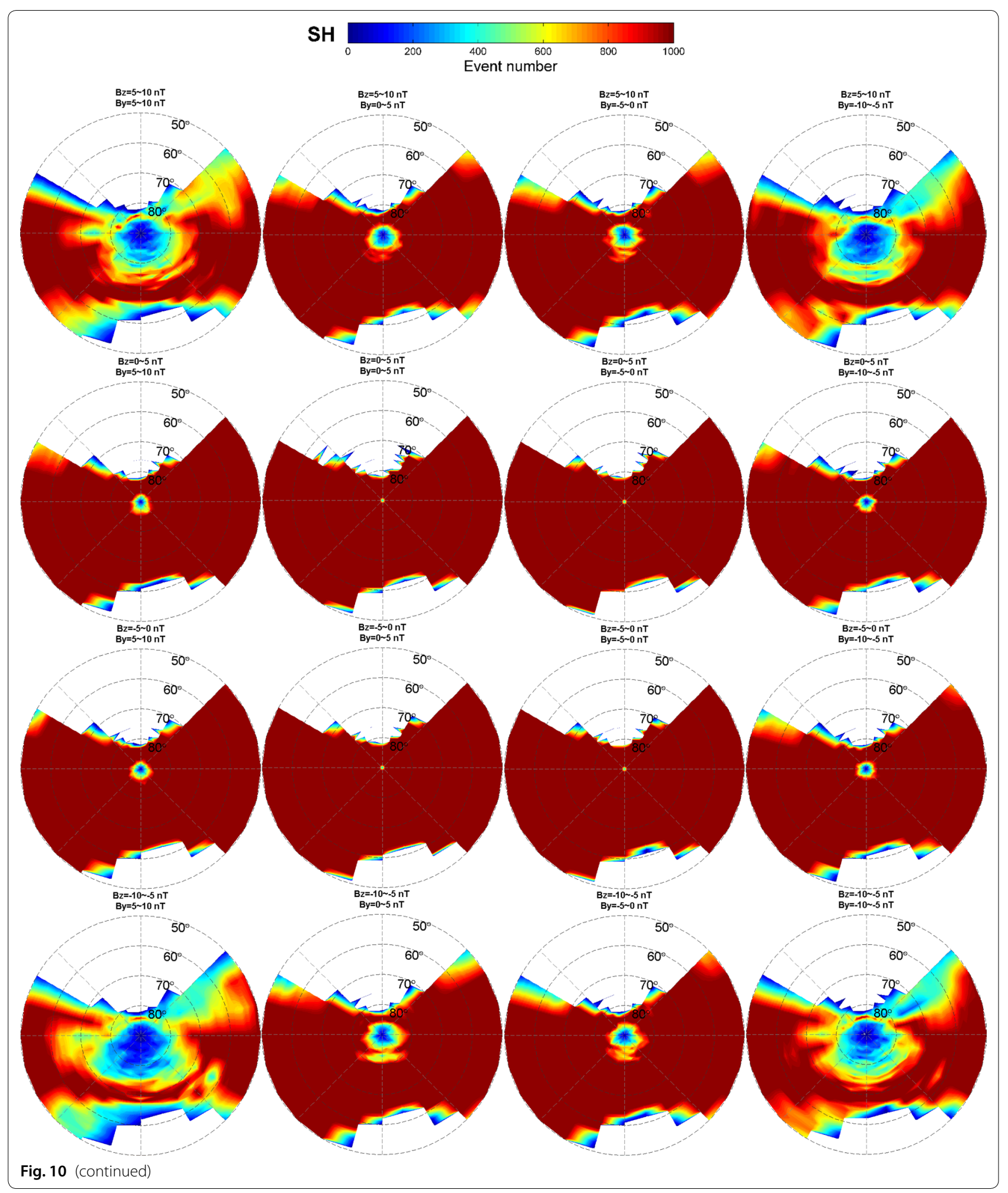


Received: 30 May 2020 Accepted: 30 September 2020

Published online: 16 October 2020

\section{References}

Anderson BJ, Takahashi K, Toth BA (2000) Sensing Global Birkeland currents with Iridium engineering magnetometer data. Geophys Res Lett 27:4045-4048. https://doi.org/10.1029/2000GL000094

Armstrong JC, Zmuda AJ (1975) Triaxial magnetic measurements of fieldaligned currents at 800 kilometers in the auroral region: initial results. J Geophys Res 78:6802-6807. https://doi.org/10.1029/JA078i028p06802

Alken P, Maus S, Lühr H, Redmon RJ, Rich F, Bowman B, O'Malley SM (2014) Geomagnetic main field modeling with DMSP. J Geophys Res Space Physics 119:4010-4025. https://doi.org/10.1002/2013JA019754

Alken P, Olsen N, Finlay CC (2020) Co-estimation of geomagnetic field and inorbit fluxgate magnetometer calibration parameters. Earth Planets Space 72:49. https://doi.org/10.1186/s40623-020-01163-9

Burke WJ, Wilson GR, Lin CS, Rich FJ, Wise JO, Hagan MP (2011) Estimating Dst indices and exospheric temperatures from equatorial magnetic fields measured by DMSP satellites. J Geophys Res 116:A01205. https://doi. org/10.1029/2010JA015310

Carter JA, Milan SE, Coxon JC, Walach M-T, Anderson BJ (2016) Average field-aligned current configuration parameterized by solar wind conditions. J Geophys Res Space Physics 121:1294-1307. https://doi. org/10.1002/2015JA021567

Cattell C, Lysak R, Torbert RB, Mozer FS (1979) Observations of differences between regions of current flowing into and out of the ionosphere. Geophys Res Lett 6:621-624. https://doi.org/10.1029/GL006i007p00621

Christiansen F, Papitashvili VO, Neubert T (2002) Seasonal variations of high-latitude field-aligned currents inferred from Ørsted and Magsat observations. J Geophys Res 107(A2):1029. https://doi.org/10.1029/2001 J A900104

Coumans V, Gérard J-C, Hubert B, Evans DS (2002) Electron and proton excitation of the FUV aurora: Simultaneous IMAGE and NOAA observations. J Geophys Res 107(A11):1347. https://doi.org/10.1029/2001JA009233

Coxon JC, Milan SE, Clausen LBN, Anderson BJ, Korth H (2014) The magnitudes of the regions 1 and 2 Birkeland currents observed by AMPERE and their role in solar wind-magnetosphere-ionosphere coupling. J Geophys Res Space Physics 119:9804-9815. https://doi.org/10.1002/2014JA020138

Coxon JC, Milan SE, Carter JA, Clausen LBN, Anderson BJ, Korth H (2016) Seasonal and diurnal variations in AMPERE observations of the Birkeland currents compared to modeled results. J Geophys Res Space Physics. https://doi.org/10.1002/2015JA022050

Dunlop MW, Yang Y-Y, Yang J-Y, Lühr H, Shen C, Olsen N, Zhang Q-H, Bogdanova YV, Cao J-B, Ritter P, Kauristie K, Masson A, Haagmans R (2015) Multispacecraft current estimates at Swarm. J Geophys Res Space Physics 120:8307-8316. https://doi.org/10.1002/2015JA021707

Edwards TR, Weimer DR, Tobiska WK, Olsen N (2017) Field-aligned current response to solar indices. J Geophys Res Space Phys 122:5798-5815. https://doi.org/10.1002/2016JA023563

Emmert JT, Richmond AD, Drob DP (2010) A computationally compact representation of Magnetic-Apex and Quasi-Dipole coordinates with smooth base vectors. J Geophys Res 115:A08322. https://doi.org/10.1029/2010J A015326

Escoubet CP, Fehringer M, Goldstein M (2001) Introduction: the cluster mission. Ann Geophys 19:1197-1200. https://doi.org/10.5194/angeo -19-1197-2001

Finlay CC, Olsen N, Tøffner-Clausen L (2015) DTU candidate field models for IGRF-12 and the CHAOS-5 geomagnetic field model. Earth Planets Space 67:157-189. https://doi.org/10.1186/s40623-015-0274-3

Frey HU, Mende SB, Carlson CW, Gérard J-C, Hubert B, Spann J, Gladstone R, Immel TJ (2001) The electron and proton aurora as seen by IMAGE-FUV and FAST. Geophys Res Lett 28:1135-1138. https://doi.org/10.1029/2000G L012352

Gérard JC, Hubert B, Meurant M, Shematovich VI, Bisikalo DV, Frey H, Mende S, Gladstone GR, Carlson CW (2001) Observation of the proton aurora with IMAGE FUV imager and simultaneous ion flux in situ measurements. J Geophys. Res 106(A12):28939-28948. https://doi.org/10.1029/2001 J A900119
Gjerloev JW, Ohtani S, lijima T, Anderson B, Slavin J, Le G (2011) Characteristics of the terrestrial field-aligned current system. Ann Geophys 29:17131729. https://doi.org/10.5194/angeo-29-1713-2011

Green DL, Waters CL, Anderson BJ, Korth H (2009) Seasonal and interplanetary magnetic field dependence of the field-aligned currents for both Northern and Southern Hemispheres. Ann Geophys 27:1701-1715. https://doi. org/10.5194/angeo-27-1701-2009

Hardy DA, Holeman EG, Burke WJ, Gentile LC, Bounar KH (2008) Probability distributions of electron precipitation at high magneticlatitudes. J Geophys Res 113:A06305. https://doi.org/10.1029/2007JA012746

Harel M, Wolf RA, Reiff PH, Spiro RW, Burke WJ, Rich FJ, Smiddy M (1981) Quantitative simulation of a magnetospheric substorm 1. Model logic and overview. J Geophys Res 86:2217-2241. https://doi.org/10.1029/ JA086iA04p02217

He MS, Vogt J, Luhr H, Sorbalo E, Blagau A, Le G, Lu G (2012) A high-resolution model of field-aligned currents through empirical orthogonal functions analysis (MFACE). Geophys Res Lett 39:L18105. https://doi. org/10.1029/2012GL053168

Hubert B, Gérard J-C, Bisikalo DV, Shematovich VI, Solomon SC (2001) The role of proton precipitation in the excitation of the auroral FUV emissions. J Geophys Res 106(A10):21475-21494. https://doi.org/10.1029/2000 J A000288

lijima T, Potemra TA (1976a) The amplitude distribution of field-aligned currents at northern high latitudes observed by TRIAD. J Geophys Res 81:2165-2174. https://doi.org/10.1029/JA081i013p02165

lijima T, Potemra TA (1976b) Field-aligned currents in the dayside cusp observed by TRIAD. J Geophys Res 81:5971-5979. https://doi. org/10.1029/JA081i034p05971

lijima T, Potemra TA, Zanetti LJ, Bythrow PF (1984) Large-scale Birkeland currents in the dayside polar region during strongly northward IMF: a new Birkeland current system. J Geophys Res 89:7441-7452. https://doi. org/10.1029/JA089iA09p07441

Kikuchi T, Lühr H, Schlegel K, Tachihara H, Shinohara M, Kitamura TI (2000) Penetration of auroral electric fields to the equator during a substorm. $J$ Geophys Res 105:23251-23262. https://doi.org/10.1029/2000JA900016

Kilcommons LM, Redmon RJ, Knipp DJ (2017) A new DMSP magnetometer and auroral boundary dataset and estimates of field-aligned cur-rents in dynamic auroral boundary coordinates. J Geophys Res Space Physics 122:9068-9079. https://doi.org/10.1002/2016JA023342

Knipp DJ, Matsuo T, Kilcommons L, Richmond A, Anderson B, Korth H, Redmon R, Mero B, Parrish N (2014) Comparison of magnetic perturbation data from LEO satellite constellations: Statistics of DMSP and AMPERE. Space Weather 12:2-23. https://doi.org/10.1002/2013SW000987

Korth $\mathrm{H}$, Anderson BJ, Waters CL (2010) Statistical analysis of the dependence of large-scale Birkeland currents on solar wind parameters. Ann Geophys 28:515-530. https://doi.org/10.5194/angeo-28-515-2010

Korth H, Zhang Y, Anderson BJ, Sotirelis T, Waters CL (2014) Statistical relationship between large-scale upward field-aligned currents and electron precipitation. J Geophys Res Space Physics 119:6715-6731. https://doi. org/10.1002/2014JA019961

Laundal KM, Finlay CC, Olsen N, Reistad JP (2018) Solar wind and seasonal influence on ionospheric currents from Swarm and CHAMP measurements. J Geophys Ress Space Physics 123:4402-4429. https://doi. org/10.1029/2018JA025387

Le G, Slavin JA, Strangeway RJ (2010) Space Technology 5 observations of the imbalance of regions 1 and 2 field-aligned currents and its implication to the cross-polar cap Pedersen currents. J Geophys Res 115:A07202. https ://doi.org/10.1029/2009JA014979

Lu Y, Deng Y, Sheng C, Kilcommons L, Knipp DJ (2018) Poynting flux in the dayside polar cap boundary regions from DMSP F15 satellite measurements. J Geophys Res 123:6948-6956. https://doi.org/10.1029/2018JA025309

Lühr H, Warnecke J, Rother MKA (1996) An algorithm for estimating fieldaligned currents from single spacecraft magnetic field measurements: a diagnostic tool applied to Freja satellite data. Geosci Remote Sens 34:1369-1376. https://doi.org/10.1109/36.544560

Lühr H, Park J, Gjerloev JW, Rauberg J, Michaelis I, Merayo JMG, Brauer P (2015) Field-aligned currents'scale analysis per-formed with the Swarm constellation. Geophys Res Lett 42:1-8. https://doi.org/10.1002/2014GL062453

Lühr H, Ritter P, Kervalishvili G, Rauberg J (2020) Applying the dual-spacecraft approach to the swarm constellation for deriving radial current density. In: Dunlop MW, Lühr H (eds) lonospheric multi-spacecraft analysis tools, 
ISSI scientific report series 17. Switzerland, Springer Nature, pp 117-140 10.1007/978-3-030-26732-2_6

Meredith NP, Horne RB, Thorne RM, Anderson RR (2003) Favored regions for chorus-driven electron acceleration to relativistic energies in the Earth's outer radiation belt. Geophys Res Lett 30(16):1871. https://doi. org/10.1029/2003GL017698

Milan SE, Lester M, Cowley SWH, Brittnacher M (2000) Dayside convection and auroral morphology during an interval of northward interplanetary magnetic field. Ann Geophys 18(4):436-444. https://doi.org/10.1007/ s00585-000-0436-9

Milan SE, Clausen LBN, Coxon JC, Carter JA, Walach M-T, Laundal K et al (2017) Overview of solar wind-magnetosphere-ionosphere-atmosphere coupling and the generation of magnetospheric currents. Space Sci Rev 206:547-573. https://doi.org/10.1007/s11214-017-0333-0

Murphy KR, Mann IR, Rae IJ, Waters CL, Frey HU, Kale A, Singer HJ, Anderson BJ, Korth H (2013) The detailed spatial structure of field-aligned currents comprising the substorm current wedge. I Geophys Res Space Physics 118:7714-7727. https://doi.org/10.1002/2013JA018979

Newell PT, Sotirelis T, Wing S (2009) Diffuse, monoenergetic, and broadband aurora: The global precipitation budget. J Geophys Res 114:A09207. https ://doi.org/10.1029/2009JA014326

Papitashvili VO, Christiansen F, Neubert T (2002) A new model of field-aligned currents derived from high-precision satellite magnetic field data. Geophys Res Lett 29:28-31. https://doi.org/10.1029/2001GL014207

Redmon RJ, Denig WF, Kilcommons LM, Knipp DJ (2017) New DMSP database of precipitating auroral electrons and ions. J Geophys Res Space Physics 122:9056-9067. https://doi.org/10.1002/2016JA023339

Redmon RJ, Peterson WK, Andersson L, Kihn EA, Denig WF, Hairston M, Coley R (2010) Vertical thermal O+ flows at $850 \mathrm{~km}$ in dynamic auroral boundary coordinates. J Geophys Res 115:A00J08. https://doi.org/10.1029/2010J A015589

Ritter P, Lühr H, Rauberg J (2013) Determining field-aligned currents with the Swarm constellation mission. Earth Planets Space 65:1285-1294. https:// doi.org/10.5047/eps.2013.09.006

Robinson RM, Zhang Y, Anderson BJ, Zanetti L, Korth H, Fitzmaurice A (2018) Statistical relations between field-aligned currents and precipitating electron energy flux. Geophys Res Lett 45:8738-8745. https://doi. org/10.1029/2018GL078718

Slavin JA, Le G, Strangeway RJ, Wang Y, Boardsen SA, Moldwin MB, Spence HE (2008) Space technology 5 multipoint measurements of near-Earth magnetic fields: Initial results. Geophys Res Lett 35:L02107. https://doi. org/10.1029/2007GL031728

Sotirelis T, Korth H, Hsieh S-Y, Zhang Y, Morrison D, Paxton L (2013) Empirical relationship between electron precipitation and far-ultraviolet auroral emissions from DMSP observations. J Geophys Res Space Physics 118:1203-1209. https://doi.org/10.1002/jgra.50157

Strangeway RJ, Russell CT, Carlson CW, McFadden JP, Ergun RE, Temerin M, Klumpar DM, Peterson WK, Moore TE (2000) Cusp field-aligned currents and ion outflows. J Geophys ReS 105(9):21129-21141. https://doi. org/10.1029/2000JA900032

Sonnerup BUO (1980) Theory of the low-latitude boundary layer. J Geophys Res 85:2017-2026. https://doi.org/10.1029/JA085iA05p02017

Southwood DJ (1977) The role of hot plasma in magnetospheric convection. J Geophys Res 82:5512-5520. https://doi.org/10.1029/JA082i035p05512
Sugiura M (1975) Identifications of the polar cap boundary and the auroral belt in the high-altitude magnetosphere-a model for field-aligned currents. J Geophys Res 80:2057-2068. https://doi.org/10.1029/JA080i016p 02057

Tanaka T (1995) Generation mechanisms for magnetosphere-ionosphere current systems deduced from a three-dimensional MHD simulation of the solar wind-magnetosphere-ionosphere coupling processes. J Geophys Res 100:12057-12074. https://doi.org/10.1029/95JA00419

Trenchi L, Kauristie K, Käki S, Vanhamäki H, Juusola L, Blagau A, Friel M (2019) ESA field-aligned currents methodology inter-comparison exercise. In: Dunlop M, Lühr H (eds) lonospheric multi-spacecraft analysis tools, ISSI Scientific Reports Series 17. Springer International Publishing, Cham 10.1007/978-3-030-26732-2

Waters CL, Anderson BJ, Liou K (2001) Estimation of global field aligned currents using the iridium ${ }^{\circledR}$ system magnetometer data. Geophys Res Letter 28:2165-2168. https://doi.org/10.1029/2000GL012725

Wang H, Lühr H, Ma SY (2005) Solar zenith angle and merging electric field control of field-aligned currents: A statistical study of the Southern Hemisphere. J Geophys Res 110:A03306. https://doi.org/10.1029/2004J A010530

Wang H, Ridley AJ, Lühr H (2008) SWMF simulation of field-aligned currents for a varying northward and duskward IMF with nonzero dipole tilt. Ann Geophys 26:1461-1477. https://doi.org/10.5194/angeo-26-1461-2008

Wang H, Lühr H, Zheng Z, Zhang K (2019) Dependence of the equatorial electrojet on auroral activity and in situ solar insulation. J Geophys Res. https ://doi.org/10.1029/2019JA027320

Wing S, Ohtani S, Newell PT, Higuchi T, Ueno G, Weygand JM (2010) Dayside field-aligned current source regions. J Geophys Res 115:A12215. https:// doi.org/10.1029/2010JA015837

Weimer DR (2001) Maps of ionospheric field-aligned currents as a function of the interplanetary magnetic field derived from dynamics explorer 2 data. J Geophys Res 106:12889-12902. https://doi.org/10.1029/2000JA000295

Winglee RM (2000) Mapping of ionospheric outflows into the magnetosphere for varying IMF conditions. J Atmos Sol Terr Phys 62:527-540

Workayehu AB, Vanhamäki H, Aikio AT (2019) Field-aligned and horizontal currents in the Northern and Southern Hemispheres from the Swarm satellite. J Geophys Res 124:7231-7246. https://doi.org/10.1029/2019J A026835

Xiong C, Stolle C, Lühr H (2016) The Swarm satellite loss of GPS signal and its relation to ionospheric plasma irregularities. Space Weather 14:563-577. https://doi.org/10.1002/2016SW001439

Zhang Y, Paxton L (2008) An empirical Kp-dependent global auroral model based on TIMED/GUVI FUV data. J Atmos Solar Terr Phys 70(8-9):12311242. https://doi.org/10.1016/jastp.2008.03.008

\section{Publisher's Note}

Springer Nature remains neutral with regard to jurisdictional claims in published maps and institutional affiliations.

\section{Submit your manuscript to a SpringerOpen ${ }^{\odot}$ journal and benefit from:}

- Convenient online submission

- Rigorous peer review

- Open access: articles freely available online

- High visibility within the field

- Retaining the copyright to your article

Submit your next manuscript at $\boldsymbol{\nabla}$ springeropen.com 